\title{
TECHNOLOGICAL CHARACTERISTICS OF AUTOMATIC SUBMERGED ARC SURFACING WITH HIGH-FREQUENCY OSCILLATIONS OF ELECTRODE END
}

\author{
V.A. LEBEDEV ${ }^{1}$, S.V. DRAGAN ${ }^{2}$, Zh.G. GOLOBORODKO ${ }^{2}$, I.V. SIMUTENKOV ${ }^{2}$ and Yu.A. YAROS ${ }^{3}$ \\ ${ }^{1}$ E.O. Paton Electric Welding Institute, NASU \\ 11 Bozhenko Str., 03680, Kiev, Ukraine. E-mail: office@paton.kiev.ua \\ ${ }^{2}$ Admiral Makarov National Shipbuilding University \\ 9 Geroev Stalingrada Ave., 54025, Nikolaev, Ukraine. E-mail: simutenkov@inbox.ru \\ ${ }^{3}$ AMITI Ltd. \\ 42 Novozavodskaya Str., 54028, Nikolaev, Ukraine. E-mail: yaros.amity.mk.ua@gmail.com
}

\begin{abstract}
Applying to the electrode of HF pulsed displacements, generated by a specially-developed electromechanical generator, allows increasing the efficiency of electrode melting and providing control of geometric parameters of bead in automatic submerged arc surfacing (ASAS). The present work is aimed at the experimental evaluation of the effect of HF electrode oscillations on technological characteristics of the ASAS process of structural steels. It was found that stability of arc process and quality of deposited layer formation in ASAS with HF pulsed displacements of electrode correspond to similar characteristics for surfacing without controlling action. Analysis of oscillograms of current and arc voltage shows that HF electrode oscillations allow controlling electrode metal transfer parameters. The HF electrode end oscillations under the action of pulsed displacements lead to changes in frequency of fluctuations of arc voltage: from $15-20 \mathrm{~Hz}$ in natural drop metal transfer to the frequencies without distinctly expressed extremums, which is predetermined by refining of drops, detached from electrode. The increase in frequency of controlling action results in growth of deposition coefficient rate from $15 \mathrm{~g} /(\mathrm{A} \cdot \mathrm{h})$ without oscillations up to $22.6 \mathrm{~g} /(\mathrm{A} \cdot \mathrm{h})$ at $320 \mathrm{~Hz}$ frequency. The change in amplitude of oscillations from 0.5 up to $3 \mathrm{~mm}$ in the frequency range under study allows decreasing the share of base metal in deposited metal at 30\% overlapping of beads from 0.25 (surfacing without oscillations) to 0.14. 9 Ref., 5 Figures.
\end{abstract}

$\boldsymbol{K} \boldsymbol{e} \boldsymbol{y} \boldsymbol{w} \boldsymbol{o r d s}:$ automatic surfacing, pulsed displacement, oscillations, electrode, technological characteristics

Despite the long-time period of development, the existing technology of automatic submerged arc surfacing (ASAS) attracts attention of researchers due to its potential of increase in the quality of deposited layer and efficiency [1]. The capabilities of ASAS may be realized in full through various methods of control of the electrode metal transfer and the properties of deposited layer. Electrical, mechanical and magnetic methods, as well as their combinations, are most actively used for this purpose [2, 3]. The combination of several methods allows selecting the most efficient parameters of controlling action, however as a rule, such an approach is expensive [3]. The similar effect, but a less expensive one, may be reached through electromechanical method, realized by using the generator of HF pulsed displacements of electrode $[4,5]$ in combination with a serial welding equipment.
The principle of this method consists of control of electrode metal transfer process by periodical forced removal of the liquid-metal layer from electrode end in the form of drops, which mass is determined by the frequency of vibration action. The latter, generated by the generator of pulsed displacements via a striker, is applied to the electrode at the stickout area in compliance with the schemes, given in [4].

The transverse HF (up to $10 \mathrm{kHz}$ ) mechanical pulsed action on electrode wire allows controlling the sizes of deposited bead and efficiency of process in ASAS. The investigations showed [4] that in this case the depth of penetration and the share of base metal in deposit can be 3 times reduced, and the electrode melting coefficient can be increased by 10-12\%.

The present work is aimed at the experimental evaluation of effect of HF electrode oscillations on technological characteristics of the process of ASAS of assemblies and parts of structural steels (crane wheels, brake drum pulleys, etc.), subjected to intensive wear. 
Welding Production Chair of Admiral Makarov National Shipbuilding University

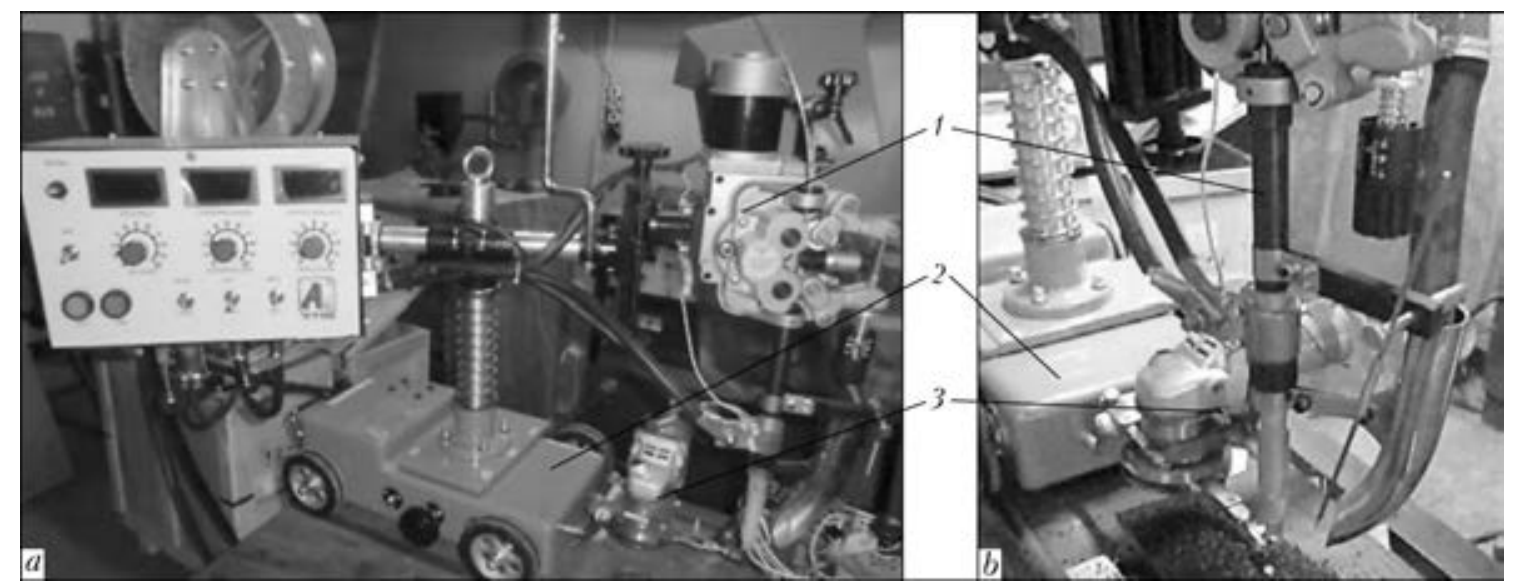

Figure 1. Options of arrangement of generator of pulsed displacements of electrode wire on welding tractor: $a, b-$ transverse to and along the deposited bead, respectively; 1 - welding head; 2 - carriage of tractor; 3 - mechanical generator

The program of experimental investigations and the evaluation of the obtained results were carried out using the facilities of the Admiral Makarov National Shipbuilding University, AMITI Company, and the E.O. Paton Electric Welding Institute of the NAS of Ukraine.

The investigations were carried on the stand, consisting of AST 1000 welding complex (inverter power source which forms a dropping voltampere characteristic, and welding tractor) and generator of $\mathrm{HF}$ pulsed displacements of electrode (Figure 1), which is fixed on the welding head, equipped with the arc voltage adjustment system by the effect on the wire feed rate. The application of the stabilized power source allowed making deposition with electrode oscillations (by secondary disturbing effect) at minimum admissible current, preserving the high stability of process, and the rate, recommended by the standard documents [6].

The stability of the surfacing process and the effect of electrode oscillations on the nature of metal transfer were evaluated by oscillograms of current and arc voltage, registered via electronic USB-oscillograph and statistically processed using the package LabView 2013 applied programs.
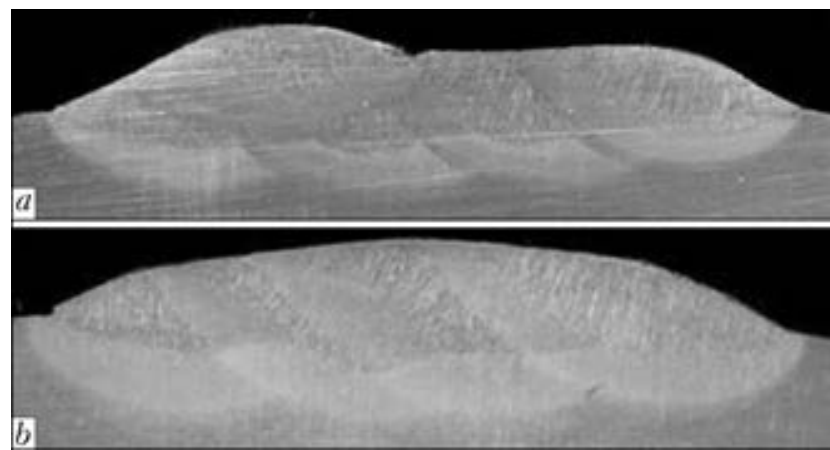

Figure 2. Macrosections of deposited layer made without (a) and with (b) HF oscillations of electrode
The deposition of beads was carried out on the specimens of $500 \times 200 \times 10 \mathrm{~mm}$ size, made of structural steel VSt3sp (killed). In compliance with the recommendations [6], the following combinations were used as welding consumables: wire Sv-08A + flux OSTs-45, and wire Sv08G2S + flux ANK-18. Surfacing condition parameters were also set up in compliance with [6] $d_{\mathrm{e}}=2 \mathrm{~mm} ; I_{\mathrm{s}}=200-250 \mathrm{~A} ; U_{\mathrm{a}}=27-30 \mathrm{~V} ; v_{\mathrm{s}}=$ $=18-22 \mathrm{~m} / \mathrm{h}$. In all the cases, the HF pulsed displacements were applied normal to electrode axis, but along the deposited bead. The parameters of the condition of electrode wire end oscillations were changed within the following limits: frequency $f_{\text {osc }}=250-9000 \mathrm{~Hz}$, amplitude $A_{\text {osc }}=$ $=0.5-3 \mathrm{~mm}$. In all the cases, the selection criteria for efficient parameters of oscillation conditions were the technological stability of process and the quality of deposited layer formation. Stability of arc process was evaluated by oscillograms of current and voltage. The quality of the deposited beads formation was evaluated by visual inspection and measurement. The deposition coefficient was determined by the standard techniques [7]. Geometric parameters of the deposited beads and the share of base metal were determined by macrosections (Figure 2).

The effect of the mechanical HF oscillations of electrode on the stability of deposition process was evaluated continuously by oscillographic testingy of current and voltage, starting the process without electrode oscillations, and continuing it with oscillations.

It should be noted that the peculiarity of the metal transfer control by the electrode transverse oscillations is the absence of change in arc length and related voltage fluctuations, predetermined by the control process itself, in contrast, for example, to process at pulsed wire feed [2]. The mentioned fact makes identification of effect of 

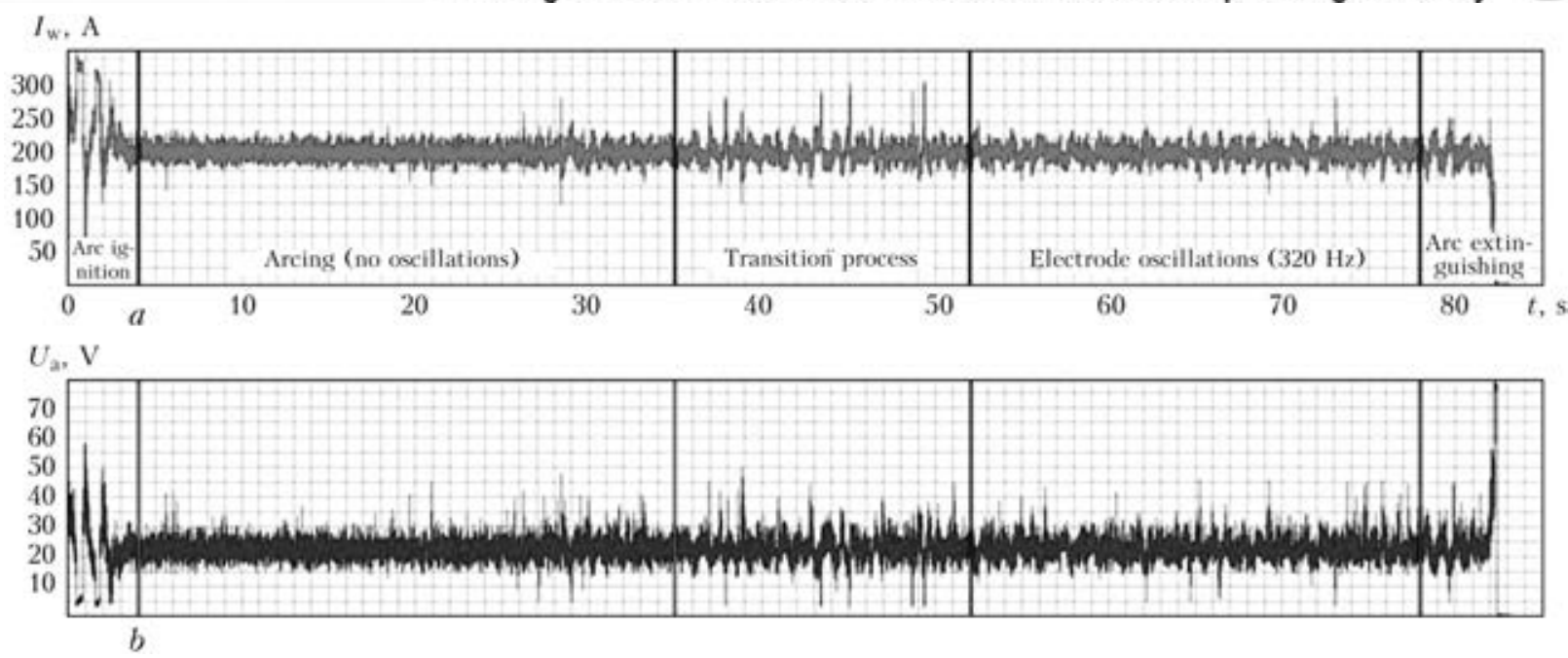

Figure 3. Oscillograms of current $(a)$ and arc voltage $(b)$ in deposition at $d_{\mathrm{e}}=2 \mathrm{~mm}, l_{\mathrm{st}}=50 \mathrm{~mm}, I_{\mathrm{S}}=200 \mathrm{~A}, U_{\mathrm{a}}=$ $=30 \mathrm{~V}, v_{\mathrm{s}}=21 \mathrm{~m} / \mathrm{h}$ and $f_{\text {osc }}=320 \mathrm{~Hz}$

electrode oscillations on metal transfer difficult. In this connection, the surfacing was performed under conditions, characterized by the process of coarse drop metal transfer, distinctly visible on the oscillograms (Figure 3) [8]. The oscillograms show areas of arc ignition, deposition without oscillations, transition process (at starting generator of pulsed displacements), deposition with electrode oscillations and arc extinguishing.

During deposition with electrode oscillations, despite a certain increase in amplitude of current and voltage fluctuations, the stability of process remains high. There are typical periodical changes of the investigated parameters, confirming the occurrence of controlling process of removal of the liquid-metal layer from the electrode end. The confirmation is the results, obtained from the oscillograms, processed by the Fourier transformation (Figure 4).

The analysis of oscillograms shows that oscillations of arc voltage with frequency $15-20 \mathrm{~Hz}$ (see Figure 4, $a$ ), typical for the natural drop metal transfer, are transformed into the spectrum of frequencies without distinctly expressed peaks (see Figure 4, $b$ ), which is related to the reducing

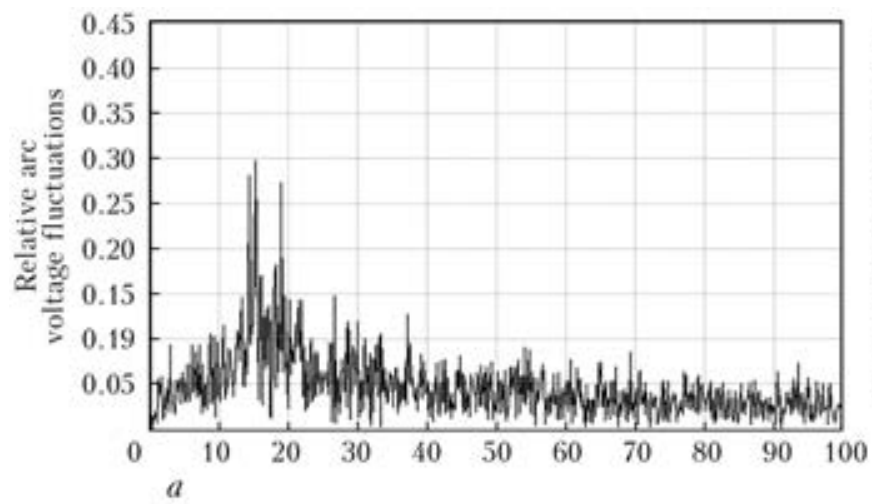

effect of the drops, refined by HF oscillations, on voltage and current in the arc. The appearance of voltage peaks of $1-2 \mathrm{~Hz}$ is related to high-amplitude oscillations $\left(A_{\mathrm{osc}}>3 \mathrm{~mm}\right)$, generated by the generator of pulsed displacements.

During deposition without and with electrode oscillations at frequency from $0,250,305$ up to $350 \mathrm{~Hz}$, the deposition coefficient grows as follows, $\mathrm{g} /(\mathrm{A} \cdot \mathrm{h}): 15.0-15.2 ; 17.9-18.2 ; 19.6-20.0$; $22.4-22.6$, that is confirmed by the calculation results obtained earlier [9].

Such a change in deposition coefficient is related to the fact that with growth of frequency of electrode oscillations, the thickness of liquidmetal layer on the electrode wire end and the average temperature of the detached drops are decreased. Due to this, the effective efficiency factor of electrode melting by the arc, rate of electrode melting, and efficiency of surfacing process are increased. Furthermore, the geometry of deposition changes (Figure 5): depth of base metal penetration $h$ and width of bead $e$ decrease, while the height of bead $g$ increases.

The main factor, which determines the sizes of deposited bead at HF oscillations of electrode,

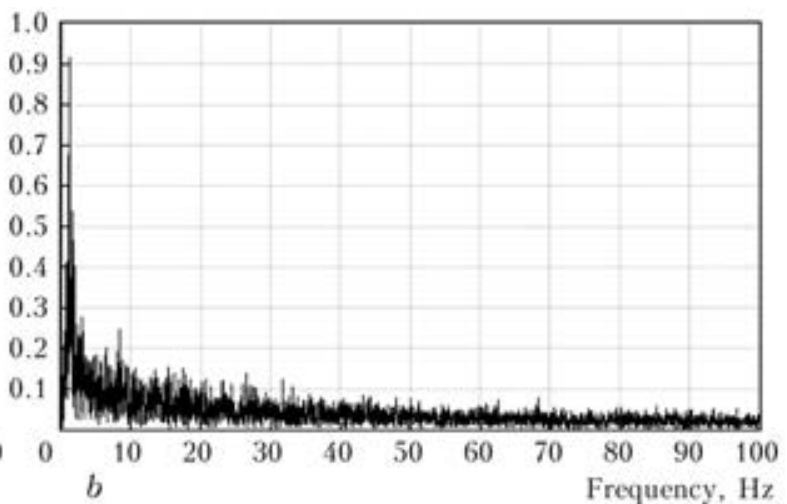

Figure 4. Frequency spectra of arc voltage in deposition without $(a)$ and with $(b)$ oscillations of electrode 


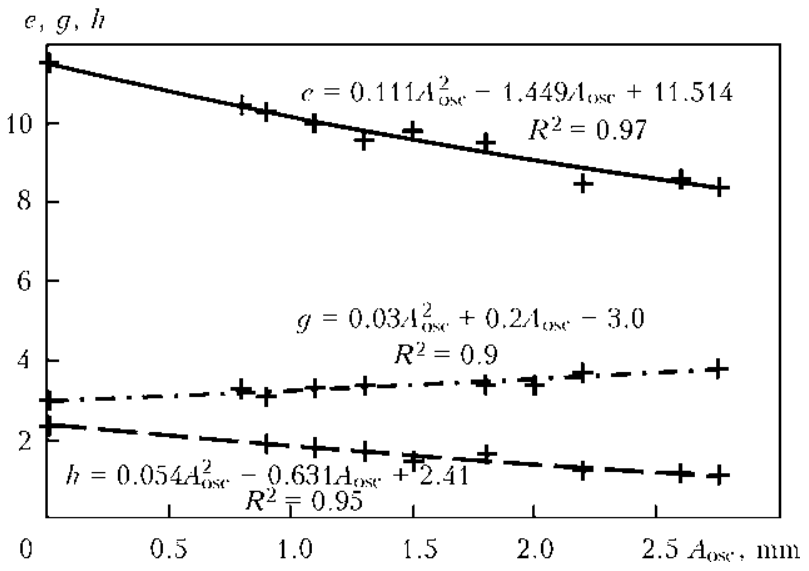

Figure 5. Effect of amplitude of $\mathrm{HF}\left(f_{\mathrm{osc}}=250-9000 \mathrm{~Hz}\right)$ pulsed displacements of electrode on geometrical parameters of deposited bead

is the amplitude of oscillations of its end. The amplitude of oscillations of the electrode wire end, when using the designed generator of pulsed displacements, is rather easy to control by the selection of point of applying of pulsed action at the electrode stickout and the change in frequency of pulsed displacements. In addition, the amplitude of electrode end oscillations can be regulated by the change in stickout length, however this is possible only in those cases, when the stickout length can be quite easily changed (deposition by wires of larger diameters of $4^{-}$ $6 \mathrm{~mm}$ of steel with a low specific resistance).

With increase in frequency the amplitude of oscillations is proportionally growing, thermal and force effect of arc and drops of electrode metal on weld pool is decreased, hence, depth of penetration $h$ and share of base metal in the deposited layer are decreased. Thus, the share of base metal during deposition with $30 \%$ overlapping of beads without electrode oscillations amounts to 0.25 , while with electrode oscillations it amounts to 0.14 , being the positive factor of saving welding consumables in surfacing.

To obtain the quantitative evaluation of effect of oscillations amplitude on the sizes of bead in deposition with HF oscillations of electrode, the experimental data (see Figure 5) were approximated by quadratic polynomials with sufficient accuracy for practice (mean-square deviation $\left.R^{2} \geq 0.9\right)$.

The obtained results give grounds to consider that the technology of the ASAS of structural steels with HF oscillations of electrode is reasonable for repair of propeller drive shafts and crane wheel flanges in accordance with the requirements of RD 212.0080-87 (covering ship mechanisms and devices, parts of mechanisms of handling machinery of ports and hydraulic and engineering structures) [6].

\section{Conclusions}

1. The pulsed displacement, applied to electrode wire, which in its turn causes HF electrode end oscillations, allows controlling technological characteristics of process and geometrical characteristics of bead in ASAS of structural steels.

2 . With increase in frequency of pulsed displacements the amplitude of electrode oscillations is growing proportionally, reaching $3 \mathrm{~mm}$ at $320 \mathrm{~Hz}$. Furthermore, the deposition coefficient is growing from 15.0 up to $22.6 \mathrm{~g} /$ (A.h) without decrease in stability of arc process, depth of penetration is 3 times increased, height of deposited bead increases by $30 \%$.

1. Lashchenko, G.I. (1998) Energy characteristics of processes of consumable electrode arc welding. Avtomatich. Svarka, 9, 18-23.

2. Lebedev, V.A. (2008) Aspects of selection of equipment for electric arc and automatic welding with pulse feed of electrode wire. Svarochn. Proizvodstvo, 5, 45-49.

3. Paton, B.E., Lebedev, V.A., Mikitin, Ya.I. (2006) Method of combined control of electrode metal transfer process in mechanized arc welding. Ibid., 8, 27-32.

4. Goloborodko, Zh.G., Dragan, S.V., Simutenkov, I.V. (2013) Automatic submerged arc surfacing of structural steels with transverse high-frequency movements of electrode. The Paton Welding J., 6, 34-37.

5. Simutenkov, I.V., Dragan, S.V., Gal, A.F. Device for electrode wire feed. Pat. 104894 Ukraine. Fil. 21.12.2011. Publ. 25.03.2014.

6. $R D$ 212.0080-87: Guiding document on standardization. Rules. Automatic submerged arc surfacing of steel cylindrical parts with carbon and corrosionresistant steel. Fundamentals. Introd. 01.03.88.

7. Leskov, G.I. (1970) Electric welding arc. Moscow: Mashinostroenie.

8. Paton, B.E., Lebedev, V.K. (1966) Electric equipment for arc and electroslag welding. Moscow: Mashinostroenie.

9. Dragan, S.V., Simutenkov, I.V., Ignatenkov, O.V. (2012) Procedure for determination of parameters of electrode high-frequency mechanical oscillations in automatic submerged arc surfacing. Visnyk DDMA, 3, 124-129.

Received 30.50.2014 